\title{
Evaluación experimental y análisis de la mejora con aislamiento para el caso del puente térmico en el frente de forjado
}

\section{Experimental assessment of improvements in thermal performance from insulating the thermal bridge at the edge of a floor slab}

\author{
N. Arias Jiménez $^{(*)}$, A. Bobadilla Moreno ${ }^{(* *)}$
}

\section{RESUMEN}

El presente artículo plantea su problemática a partir de la necesidad del mejoramiento de la calidad térmica de la envolvente en el complejo de muros, específicamente en hormigón armado (material predominante para edificación en altura en Chile). Considerar la opción de aislación por la cara interior del muro produce, como consecuencia, la interrupción del material aislante en el encuentro del forjado y los muros perimetrales, generando el puente térmico conocido como frente de forjado. Ante esto se propone conocer el impacto de dicho puente, evaluando su comportamiento como singularidad mediante ensayos experimentales (cámara térmica). Posteriormente los resultados se integrarán a un caso de estudio que permita establecer la influencia del puente en el comportamiento energético global de una edificación a través de simulaciones térmicas con el software Tas. Finalmente se concluye una baja incidencia en las pérdidas de calor interior, tomando relevancia el comportamiento de las temperaturas superficiales.

Palabras clave: puente térmico; frente de forjado; método de cámara térmica; aislación térmica.

\section{ABSTRACT}

The problematic of the article rises from the need of improving the thermal quality of the built envelope in the wall complex, specifically in the case of reinforced concrete (most used material in high-rise housing in Chile). Considering the use of insulation on the inside face of the wall, interrupts the continuity of the insulating material where the mezzanine slab and the perimeter walls meet, generating a thermal bridge known as mezzanine front. The purpose then, is to know the impact of the mentioned thermal bridge studying its properties through experimental tests on a thermal chamber. Later, the results will be integrated to a case of study that allows establishing the incidence of the bridge in the overall energetic behavior of through the integration of the results into the Thermal Analysis Simulation software (Tas). Finally, it is concluded a low incidence in the inner heat loses, becoming relevant the behavior of the superficial temperatures.

Keywords: thermal bridge; edge of a floor slab; guarded hotbox method; thermal insulation.

(*) Universidad del Bío-Bío, Concepción (Chile).

(**) Centro de Investigación en Tecnologías de la Construcción (CITEC), Universidad del Bío-Bío, Concepción (Chile).

Persona de contacto/Corresponding author: narias@ubiobio.cl (N. Arias Jiménez)

ORCID: http://orcid.org/oooo-0003-1782-7314 (N. Arias Jiménez);

http://orcid.org/oooo-0oo3-2781-5325 (A. Bobadilla Moreno)

Cómo citar este artículo/Citation: Arias Jiménez, N., Bobadilla Moreno, A. (2016). Evaluación experimental y análisis de la mejora con aislamiento para el caso del puente térmico en el frente de forjado. Informes de la Construcción, 69(546): e188, doi: http://dx.doi. org/10.3989/ic.15.151.

Copyright: (C) 2017 CSIC. Licencia / License: Salvo indicación contraria, todos los contenidos de la edición electrónica de Informes de la Construcción se distribuyen bajo una licencia de uso y distribución Creative Commons Attribution License (CC BY) Spain 3.o. 


\section{INTRODUCCIÓN}

El escenario energético nacional referido al sector edificación se ha transformado en una preocupación latente, debido a que este último representa un consumo de un 25,8\% del total de la energía del país (1). Por lo que disminuir el consumo energético, junto con aumentar el confort térmico, se presenta como uno de los grandes desafíos para un país que aún cuenta con una amplia cantidad de viviendas deficientes térmicamente.

Si se toma como dato la cobertura de la Reglamentación sobre Acondicionamiento Térmico de Viviendas (MINVU), representada por sus etapas en vigencia "Aislación de techumbre» (2000) y «Aislación de muros, ventanas y pisos ventilados» (2007), tenemos que en la práctica solamente los proyectos de viviendas recepcionados a partir del año 2007 cuentan con las soluciones de aislaciones térmicas antes planteadas. Quedando un $74 \%$ de viviendas que no se encuentran acogidas a ninguna exigencia térmica, que son las viviendas construidas antes del año 2000, mientras que un 19\% se encuentran acogidas a la primera etapa, es decir, sólo cuentan con aislación de techumbre, correspondiente a las viviendas construidas entre los períodos marzo del 2000 y febrero del 2007 (2). Estableciendo para el ítem aislación de muros el porcentaje de cobertura más desfavorable, lo que trae consigo un gran número de casos abiertos a proyectos de reacondicionamiento térmico.

Además, si se considera que los materiales predominantes para muros en el país durante el año 2011 están distribuidos con un $41,7 \%$ para hormigón y otras combinaciones, $24,5 \%$ para ladrillo y otras combinaciones y el resto de los materiales, entre los que se destacan: madera, metal, panel preformado y otros, cubren el 33,8\% (3). Esto hace deducible que gran parte de los proyectos de reacondicionamiento térmico estarán asociados al hormigón o a la albañilería como materialidad, donde la solución estará dada agregando una capa de aislación por la cara exterior del paramento o bien por la cara interior de éste.

La opción de aislar por la cara exterior del muro presenta dentro de sus ventajas: la protección de los paramentos perimetrales frente a la lluvia con viento en invierno y el soleamiento de verano; no disminuir la superficie útil interior; aprovechar la masa de los muros perimetrales y por ende su capacidad térmica acumuladora, contribuyendo con esto a la amortiguación de la fluctuación térmica del espacio interior. A diferencia de lo anterior en las soluciones de aislación por la cara interna del paramento, se separa el espacio habitado de la masa térmica del muro, lo que es recomendable si se requiere una respuesta rápida por parte de los equipos de calefacción. Por otro lado entrega una alternativa eficiente cuando se trata de rehabilitación térmica en edificios patrimoniales que cuenten con ornamentación en fachadas, situación que haría compleja una solución de aislamiento por el exterior del paramento. Lo mismo sucede cuando existe la iniciativa de mejorar la envolvente térmica de un edificio de departamentos en uso y no se logra un acuerdo con todos los propietarios para aislar por la cara exterior, la aislación por la cara interior del muro se transforma en opción para las unidades habitacionales que lo requieran.
Dichos sistemas de aislación presentan ventajas o desventajas dependiendo de los requerimientos o limitaciones que presente cada proyecto. Sin embargo, cuando estamos frente a edificaciones de más de un piso la opción de aislar por la cara interior, a diferencia de la exterior, presenta la discontinuidad de la envolvente, producto de la interrupción de la capa de aislación en el encuentro del forjado ${ }^{1}$ con el muro perimetral, dando espacio a un potencial puente térmico denominado «Puente térmico, frente de forjado» (Figura 1).

Dentro de los efectos físicos de los puentes térmicos figuran los intercambios puntuales de calor, los cuales pueden generar en régimen de invierno incrementos de hasta un $30 \%$ en la demanda de calefacción (4). El otro efecto asociado es la variación de temperaturas superficiales, lo que trae como consecuencia condensaciones superficiales e intersticiales, las primeras responsables de una patología directa y evidente que es la formación de mohos (5). Mientras que la condensación intersticial no sólo deteriora la calidad estructural del cerramiento que conforma la edificación sino que también afecta su calidad térmica, ya que la condensación de vapor de agua en los materiales aislantes aumenta su conductividad y por ende implica una baja o bien la pérdida de sus propiedades de aislación.

Desde la perspectiva de la reglamentación térmica chilena, la que logra su carácter de exigencia a través del artículo 4.1.10 de la Ordenanza General de Urbanismo y Construcciones (6) no plantea de manera drástica el control de los puentes térmicos, sino más bien deja abierta la posibilidad de su presencia, permitiendo la interrupción de la envolvente térmica por elementos estructurales y/o por tuberías o ductos de las instalaciones domiciliarias. Escorcia (2012) (7) confirma lo planteado anteriormente a través de la evaluación y diagnóstico de las condiciones constructivas y energéticas de viviendas del centro-sur de Chile en el marco de la normativa actual, donde se plantea lo permisiva de ésta frente a la ocurrencia de puentes térmicos, expresando la necesidad de replantear «el sugerir por exigir la continuidad de la envolvente térmica».

Alias (2007) (8) resalta la importancia de la atenuación de puentes térmicos en la reducción del consumo de energía en calefacción de edificios en la región nordeste de Argentina. Mediante el uso de técnicas de simulación aplicados a la mejora de la aislación y la corrección de puentes térmicos, entre los que se incluyeron los encuentros entre muros y forjados, se consiguió reducir el consumo de energía en un $24 \%$, aumentando fuertemente las expectativas respecto del ahorro energético factible de conseguir a través del control de las pérdidas puntuales.

En relación con los métodos disponibles para evaluar las pérdidas de calor y las condensaciones producidas a través de puentes térmicos, éstos van desde «métodos experimentales mediante el uso de cámara térmica calibrada y de guarda» (9), «Análisis Termográficos» (10) (11) «métodos generales de cálculo a partir de modelos geométricos» (12), «métodos simplificados y valores por defectos» (13), hasta programas informáticos como atlas digitales de valores tabulados, programas

\footnotetext{
El término forjado utilizado para denominar al elemento estructural plano y horizontal que separa los pisos o plantas de una edificación, en países como Chile, se denomina entrepiso.
} 


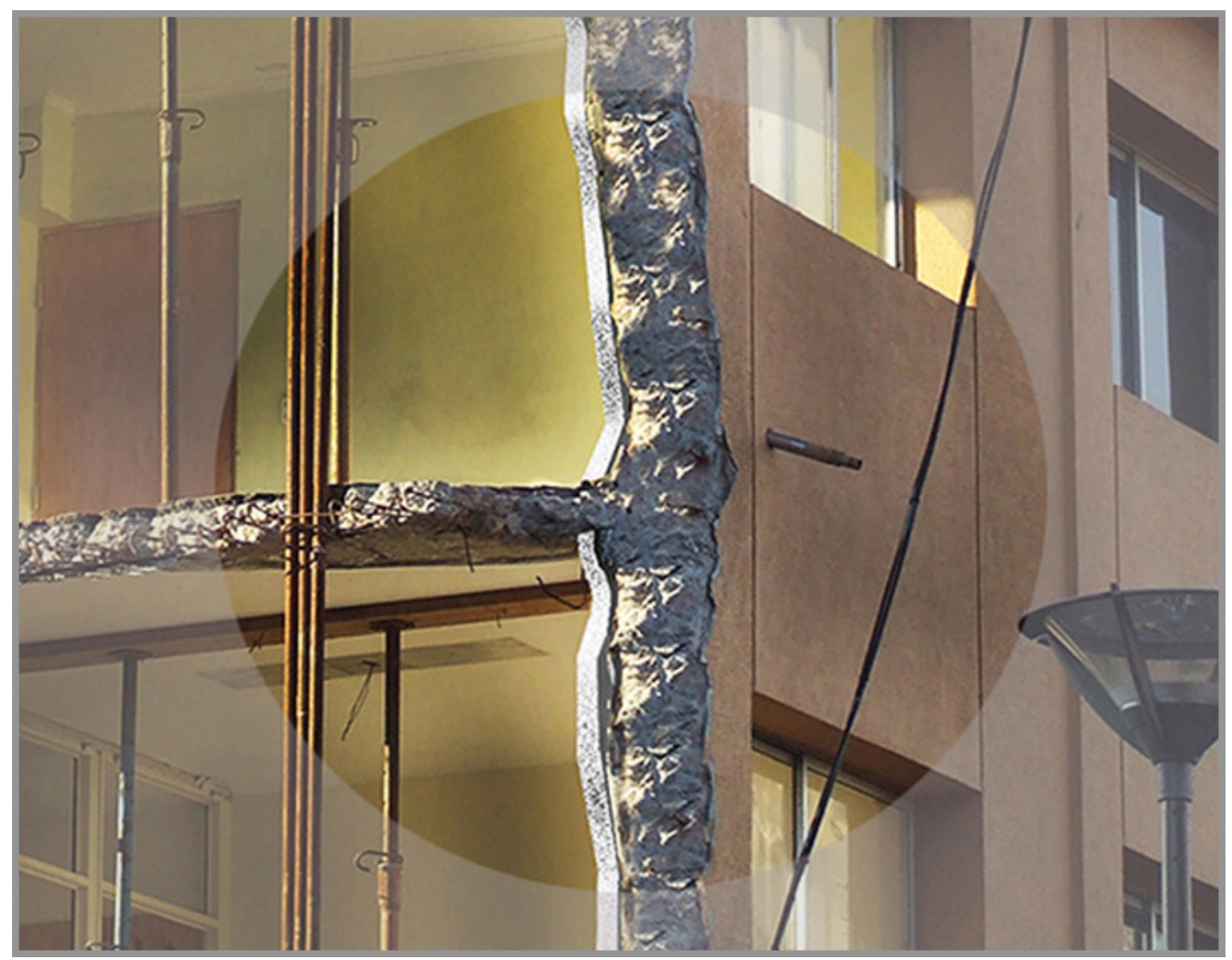

Figura 1. Fotomontaje que recrea la interrupción del material aislante en el encuentro del forjado y los muros perimetrales.

de simulación de puentes térmicos en dos dimensiones bajo régimen estacionario y programas que trabajan en tres dimensiones bajo régimen transitorio. Transformando en la actualidad a dichos programas informáticos en una herramienta de análisis altamente recurrida, debido al bajo costo económico en comparación a métodos experimentales y a la menor complejidad en relación a métodos de cálculo numérico.

Sin embargo, Tilmans (2010) (14) hace hincapié en la necesidad de validación del software como herramienta de evaluación para puentes térmicos. Y es Muñoz (2012) (15) quien establece un ejercicio de validación al analizar soluciones constructivas afectadas con puentes térmicos, utilizando dos metodologías, una a partir de simulaciones con los software Therm 6.3, Usai 2.1 y la otra con ensayo experimental, concluyendo en la superioridad de esta última opción, dado que mientras que las simulaciones se aproximan a lo real, la cámara térmica permite obtener una mirada de la realidad física del fenómeno.

A esto se suma el hecho de que el ensayo experimental es la metodología de certificación de soluciones constructivas en el contexto de la normativa nacional (9) (16) (17).

Por lo tanto, el objetivo general del presente trabajo de investigación se centrará en evaluar cuantitativa y cualitativamente el impacto del puente térmico en el frente de forjado para edificaciones de hormigón armado, ya que la información resultante se torna de gran relevancia a la hora de decidir la ubicación del material aislante y por ende la solución de envolvente térmica para el complejo de muros perimetrales.

Tomando en cuenta el valor del ensayo experimental como método de evaluación (cámara térmica de guarda). Se llevará a análisis las distintas posibilidades de aislación para dicho punto constructivo, evaluando a partir de los valores U resultantes el comportamiento de estos puntos como singularidad, posteriormente se integrarán estos resultados a un caso de estudio que permita establecer la influencia del puente térmico citado en el comportamiento energético global de una edificación, a través de simulaciones térmicas con el software Tas (18). Además se compararán las temperaturas superficiales interiores en la zona del encuentro entre losa y muro, con el fin de establecer su comportamiento frente a potenciales riesgos de condensación. Finalmente se propondrán soluciones constructivas que disipen el puente térmico, disminuyendo su impacto en las pérdidas de energía y estabilizando sus temperaturas superficiales.

\section{DESARROLLO}

Metodológicamente se plantea el proceso de obtención de datos en tres fases (Figura 2).

Fase 1: Evaluación experimental.

A partir del puente térmico en estudio (frente de forjado) y con el propósito de evaluar el comportamiento de dicho nudo ante distintas posibilidades de aislamiento se establecen 4 casos de análisis, los que serán materializados a partir de una probeta de hormigón armado y ensayado a través del método experimental en cámara térmica de guarda, procedimiento que determina propiedades de transmisión térmica en estado estacionario y otras condiciones relacionadas. Tanto el funcionamiento de la camara como las condiciones de ensayo quedan establecidas en la NCh 851 Of2008 (9) correspondiente a la ISO 8990:1994 (19).

Los casos se clasifican de la siguiente manera: 


\section{CASO DE ESTUDIO PUENTE TERMICO FRENTE DE FORJADO}

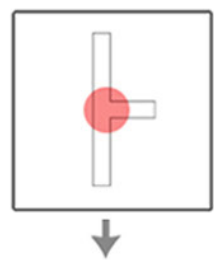

DETERMINACION DE 4 CASOS DE CONDICIONES DE AISLACION PARA EL NUDO

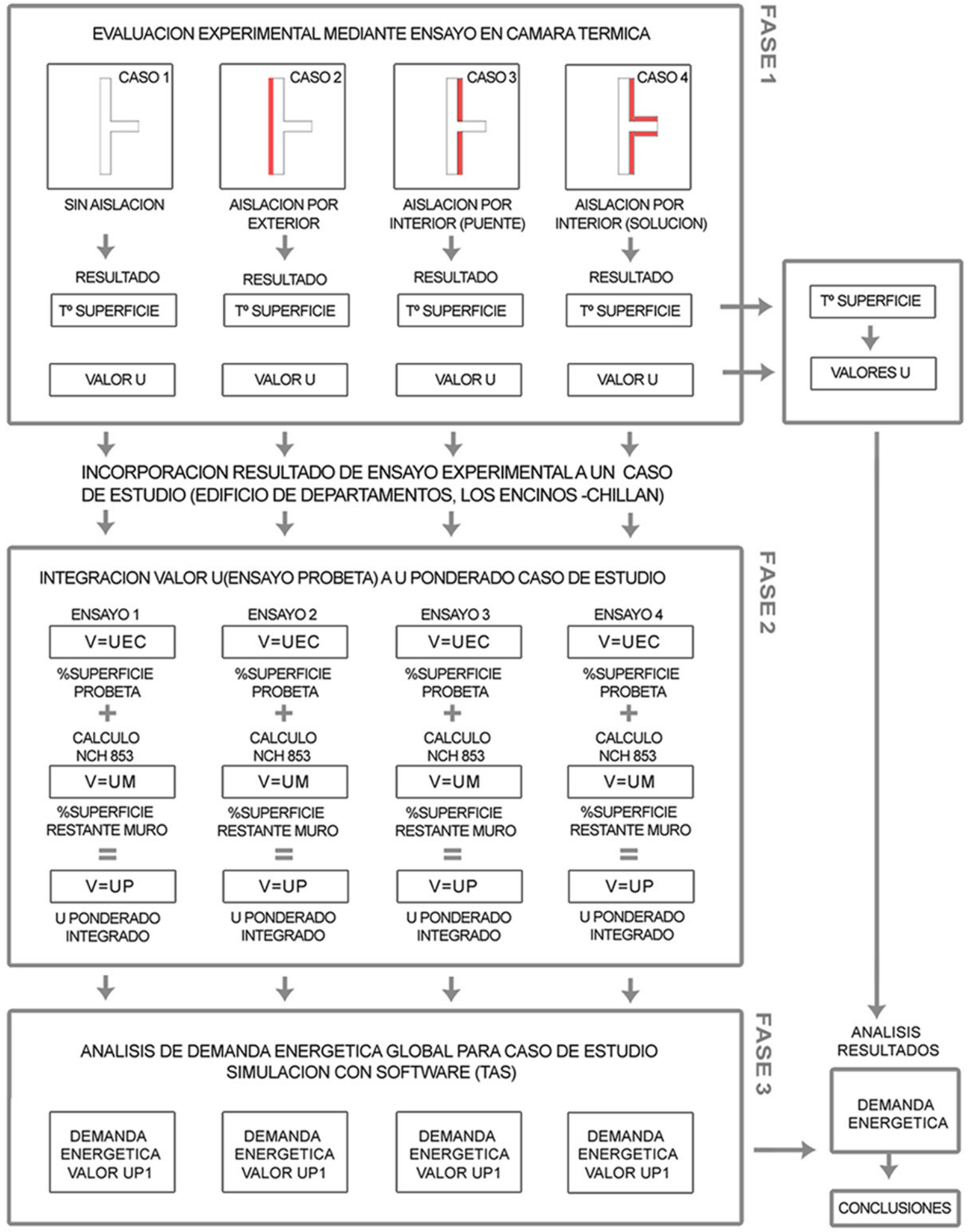

Nomenclatura: (UEC) Valor U Ensayo Cámara, (UM) Valor U Muro, calculado NCh 853, (UP) Valor U Ponderado. 
- Caso 1: sin aislación.

- Caso 2: con solución de aislación por el exterior del muro.

- Caso 3: con solución de aislación por el interior del muro (presencia de puente térmico, generado por interrupción de la aislación en un 9\% de la superficie del muro).

- Caso 4: con solución de aislación por el interior del muro (con ruptura de puente térmico).

De estos ensayos se podrá obtener un levantamiento de las temperaturas superficiales en distintos puntos del nudo como también los valores U para cada solución.

Fase 2: Incorporación de los valores U resultantes de los ensayos experimentales a un caso de estudio.

Si bien la fase experimental entregó valores U para cada uno de los casos planteados, dichos valores representan sólo el área que abarca la probeta. Por lo tanto para conocer la real incidencia del puente térmico en las demandas energéticas totales es necesario integrar los valores U resultantes a un modelo que evalúe el comportamiento global de una edificación.

Fase 3: Simulación a través del software Tas para evaluar la incidencia del puente térmico en la demanda energética de un caso de estudio que cuente con diferencias de temperaturas ambientales que sean significativas y a la vez representativas, con el fin de ampliar el alcance del análisis a otras localidades del país.
Tras la modelación se procede a comparar los resultados de cada caso y así establecer el aporte del puente térmico en las pérdidas energéticas globales.

Finalmente se analiza y concluye a partir de los resultados de la incidencia del puente térmico en las demandas energéticas globales de una edificación como también del comportamiento de las temperaturas superficiales.

\section{Fase 1: Evaluación experimental}

El diseño de la probeta recrea el encuentro del forjado con el muro perimetral. En este caso estará dado por una porción de muro de hormigón armado de $1 \mathrm{~m}^{2}$ de superficie por $15 \mathrm{~cm}$ de espesor. Que en su centro proyecta un voladizo de $40 \mathrm{~cm}$ de largo por $60 \mathrm{~cm}$ de ancho y $15 \mathrm{~cm}$ de espesor, que representa la losa del forjado en su encuentro con el paramento vertical (Figura 3).

Las dimensiones para el muro responden a los requerimientos de la cámara térmica de guarda (9) (19).

\section{Material probeta:}

- Hormigón armado H-25, espesor $15 \mathrm{~cm} . \lambda$ : 1,63 W/(mK). Para muro como losa.

- Material aislación muro: Poliestireno expandido, espesor $5 \mathrm{~cm}$. densidad $20 \mathrm{~kg} / \mathrm{m}^{3}$ y $\lambda$ : $0,0384 \mathrm{~W} /(\mathrm{mK})$.

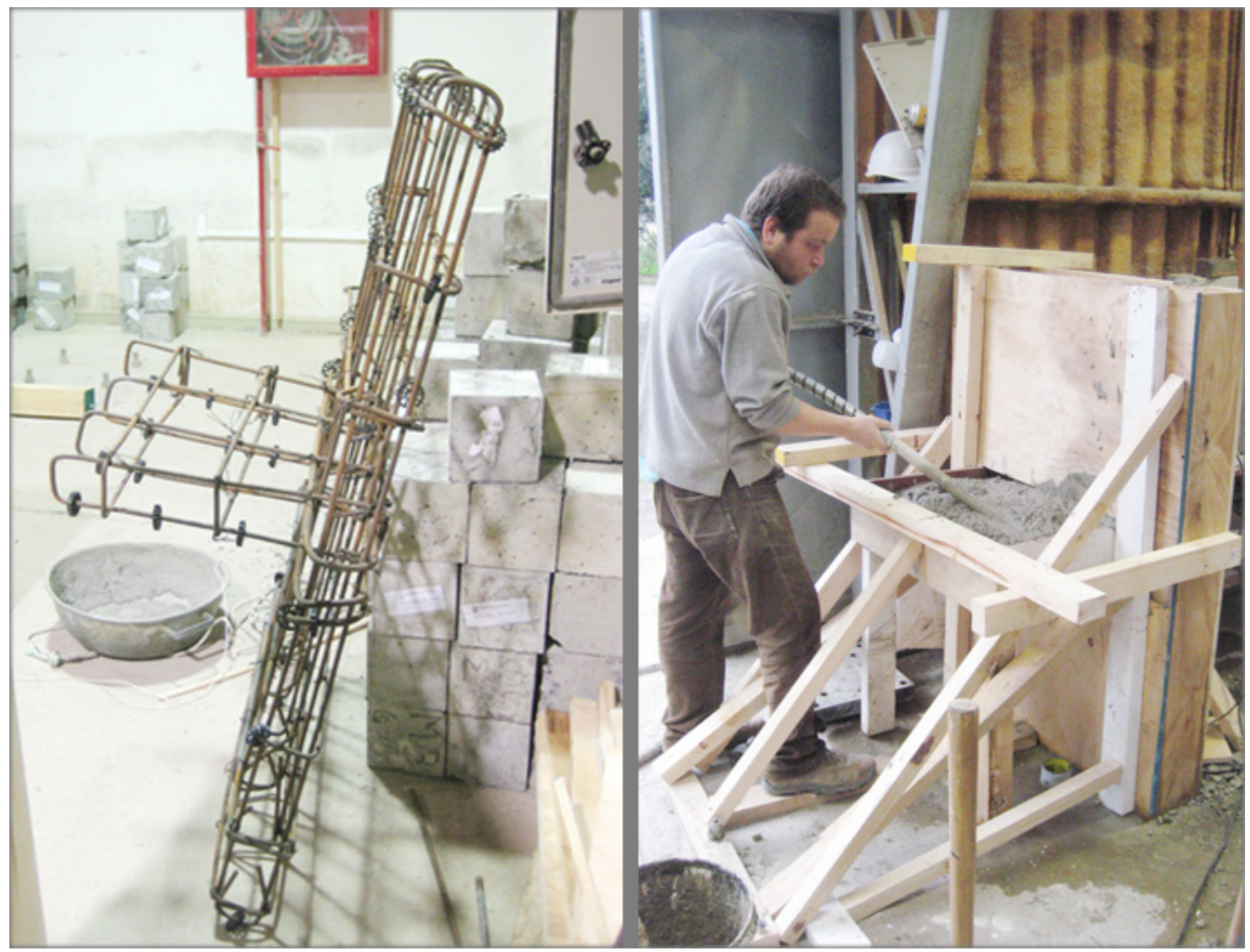

Figura 3. Proceso de elaboración de probeta de hormigón armado. 
- Material aislación losa (solución): Poliestireno expandido, espesor $1 \mathrm{~cm}$. densidad $30 \mathrm{~kg} / \mathrm{m}^{3}$ y $\lambda$ : $0,0361 \mathrm{~W} /(\mathrm{mK})$.

Cabe destacar que para los cuatro casos de análisis se incorporó al canto de la losa de la probeta una capa de aislación de poliestireno expandido de $1 \mathrm{~cm}$ de espesor y $30 \mathrm{~kg} / \mathrm{m}^{3}$ de densidad, con el fin de controlar las pérdidas y ganancias de temperatura a través de dicho canto.

Respecto del método de cámara térmica de guarda se debe agregar que ésta se encuentra diseñada para probetas de proporción vertical (ensayos de muros) que van montadas en un anillo entre una cámara caliente y una fría, representando las temperaturas interior y exterior, respectivamente. Por esta

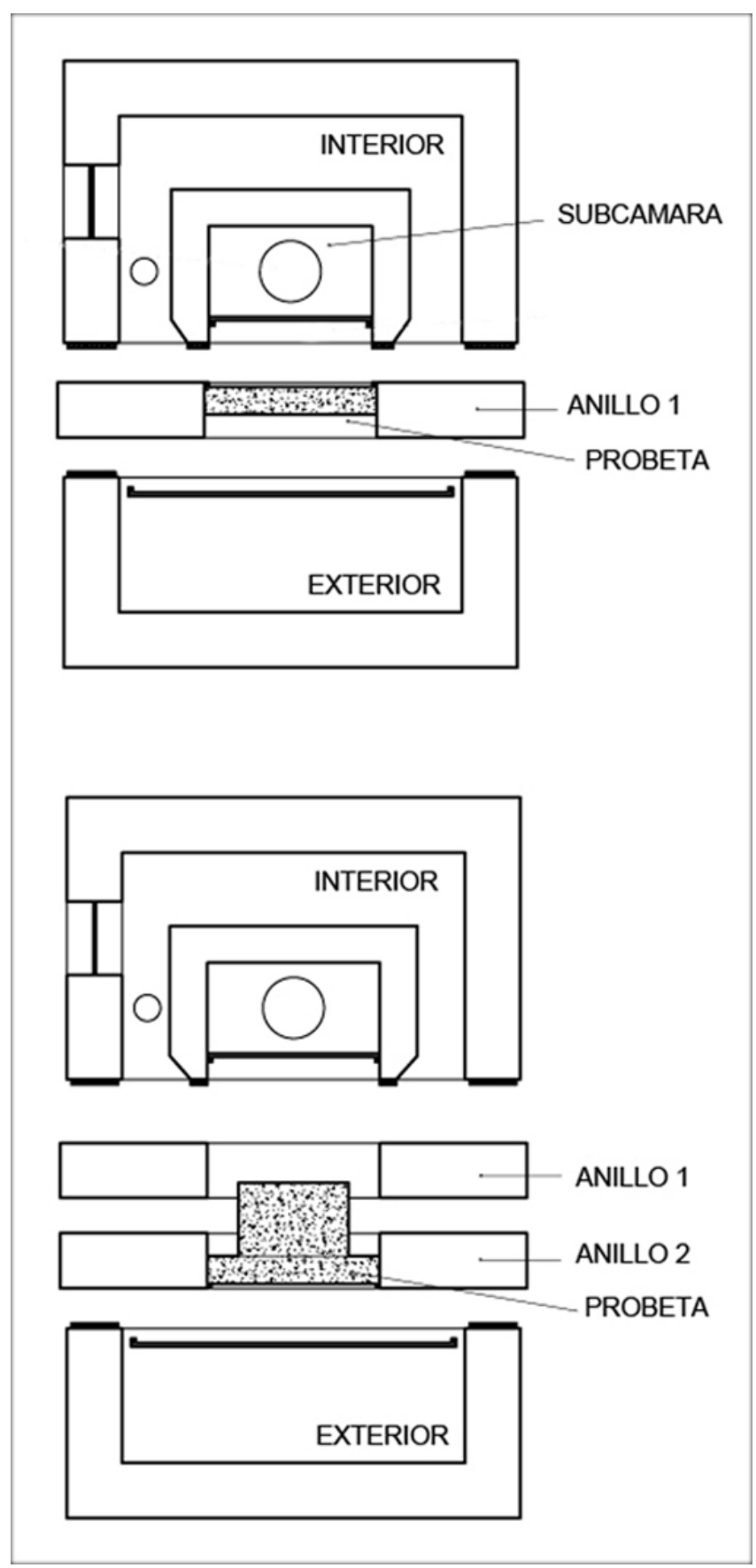

Figura 4. Esquema (planta) cámara térmica de guarda. Arriba se muestra el procedimiento para el ensayo de una probeta de muro, mientras que abajo se aprecia la adaptación que se realizó para dar cabida a la probeta que contempla el encuentro de muro y forjado. razón se debió solucionar la cabida de la probeta a ensayar, agregando un segundo anillo que permita generar la distancia necesaria para contener el volado que representa la losa del forjado (Figuras 4 y 5 ).

Las condiciones de ensayo, tales como los períodos de medición, se realizaron conforme a la NCh 851 Of20o8 (9) correspondiente a la ISO 8990:1994 (19). El método considera la instalación de 8 termocuplas de medición de aire en el lado caliente y 8 por el lado frío, donde el promedio en cada uno de los lados representa las temperaturas del ambiente interior y exterior, respectivamente. Se disponen además 8 termocuplas de medición de superficie ubicadas en ambos lados de la probeta. En el caso particular del análisis de la losa se consideró un arreglo experimental especial, ubicando termocuplas adicionales a partir del ángulo de encuentro entre la losa y el muro a $8 \mathrm{~cm}, 18 \mathrm{~cm}$ y $28 \mathrm{~cm}$, con el objeto de evaluar la caída de la temperatura conforme se acercan al punto de ruptura de la capa de aislamiento (Figuras 6, 7, 8 y 9).

El proceso de medición consideró un período de estabilización de 3 días, para proseguir con 3 días de mediciones por cada caso de estudio, con registros a un ritmo de 2 horas, entre las 8 a.m. y 8 p.m.

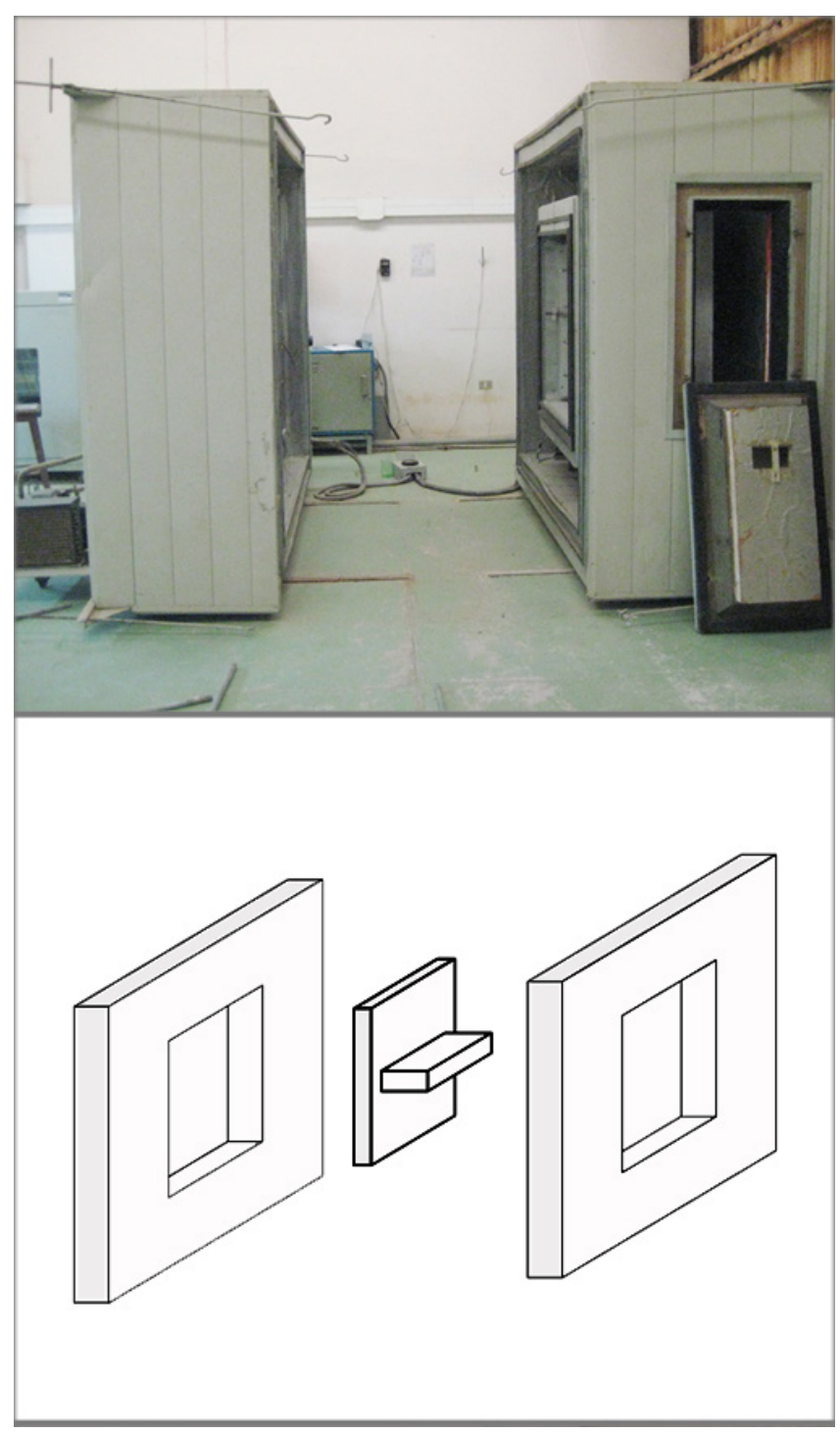

Figura 5. De arriba a abajo: cámara térmica de guarda dispuesta para recibir anillo (soporte para probeta); esquema disposición probeta en anillos 1 y 2 . 


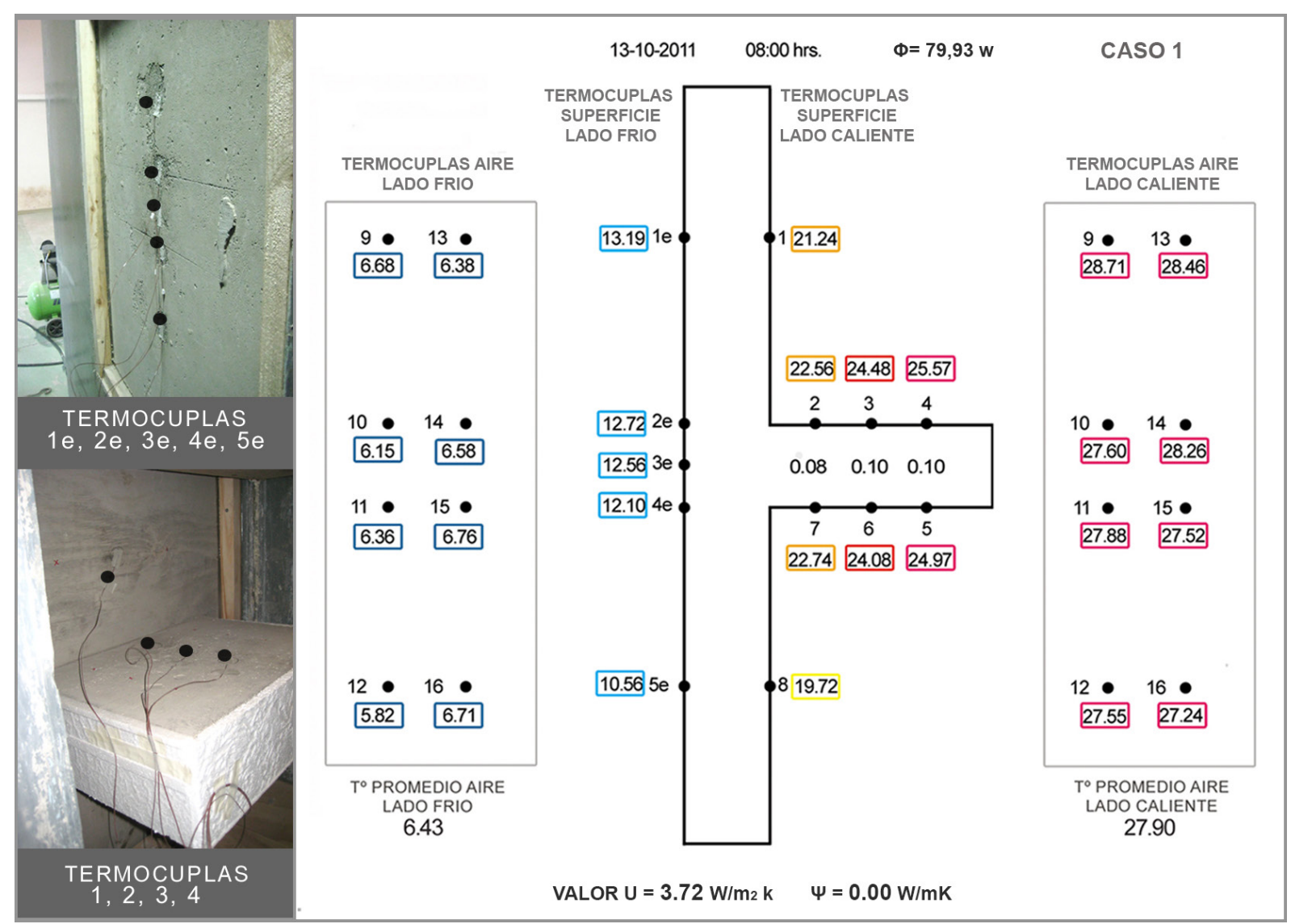

Figura 6. Valores caso 1: encuentro de forjado con muro exterior sin aislación. Material muro hormigón armado $15 \mathrm{~cm}$.

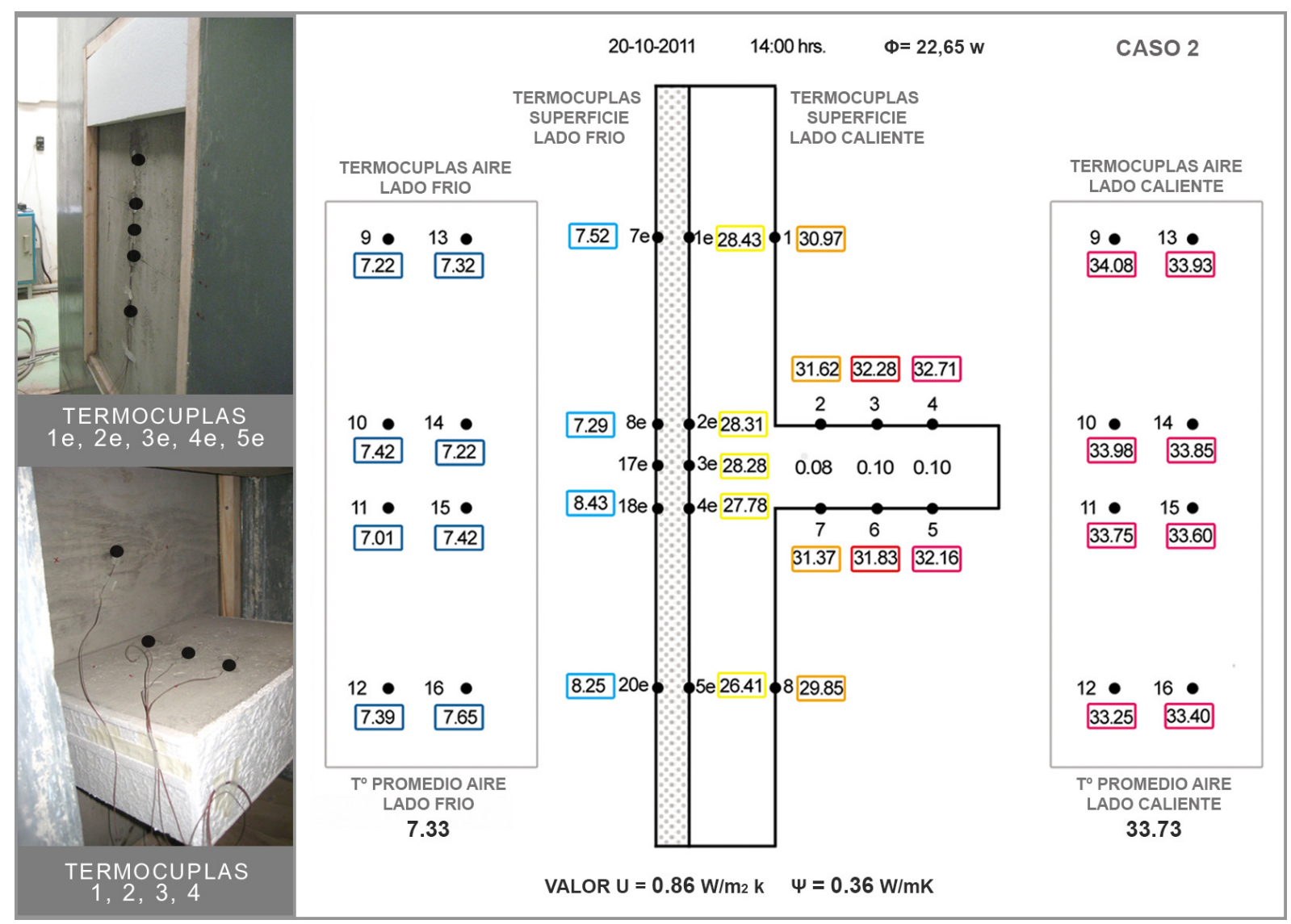

Figura 7. Valores caso 2: encuentro de forjado con muro exterior. Aislación por cara externa del muro. Material: muro hormigón armado $15 \mathrm{~cm}$. Aislación muro: poliestireno expandido dens. $20 \mathrm{~kg} / \mathrm{m}^{3}$, esp. $5 \mathrm{~cm}$. 


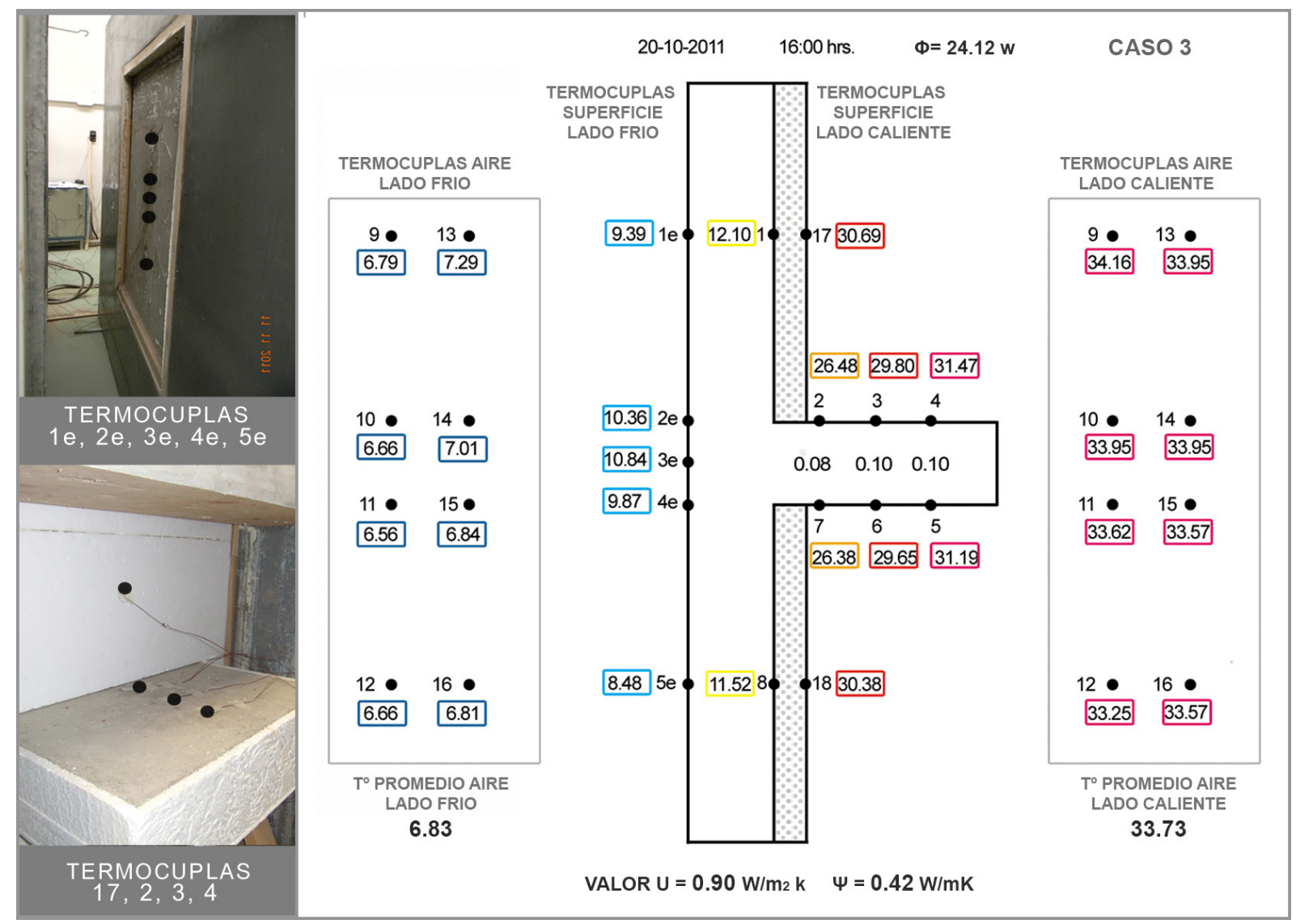

Figura 8. Valores caso 3: encuentro de forjado con muro exterior. Aislación por cara interna del muro (puente térmico). Material: muro hormigón armado $15 \mathrm{~cm}$. Aislación muro: poliestireno expandido dens. $20 \mathrm{~kg} / \mathrm{m}^{3}$, esp. $5 \mathrm{~cm}$.

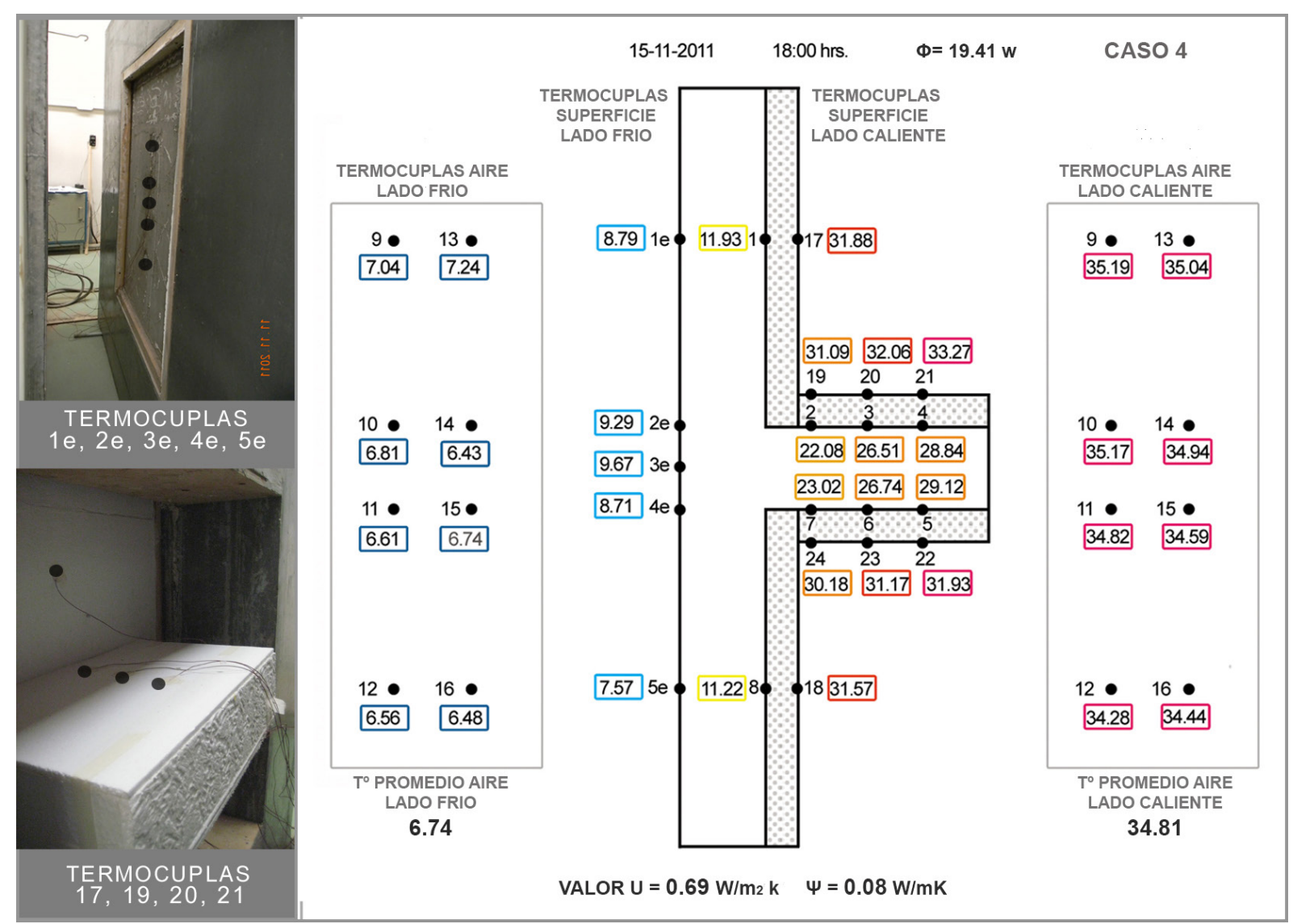

Figura 9. Valores caso 4: encuentro de forjado con muro exterior. Aislación por cara interna del muro con solución de puente a través de aislación en losa. Material: muro hormigón armado $15 \mathrm{~cm}$. Aislación muro: poliestireno expandido dens. $20 \mathrm{~kg} / \mathrm{m}^{3}$, esp. $5 \mathrm{~cm}$. Aislación losa: poliestireno expandido dens. $30 \mathrm{~kg} / \mathrm{m}^{3}$, esp. $1 \mathrm{~cm}$. 
Cada caso de estudio se sintetiza a través de una ficha (Figuras $6,7,8,9)$ que consigna datos sobre fecha y hora de la medición, flujo de Calor $\Phi(\mathrm{w})$, temperaturas del aire $\left({ }^{\circ} \mathrm{C}\right)$, temperaturas superficiales $\left({ }^{\circ} \mathrm{C}\right)$, valor $\mathrm{U}$ del ensayo (W/ $\mathrm{m}^{2} \mathrm{~K}$ ) y finalmente el valor de la transmitancia térmica lineal $\Psi(\mathrm{W} / \mathrm{mK})$.

Este último valor fue despejado de la ecuación [1] (20), utilizando datos experimentales resultantes del ensayo, exceptuando el valor $\mathrm{U}_{\mathrm{m}}$ (valor $\mathrm{U}$ sin considerar puentes térmicos) que fue calculado de forma manual a partir de la NCh 853 . Of91 (17).

$$
\Phi_{\mathrm{T}}=\left(\mathrm{U}_{\mathrm{m}} \mathrm{A}+\Psi \mathrm{L}\right)\left(\mathrm{q}_{\mathrm{i}}-\mathrm{q}_{\mathrm{e}}\right)
$$

\section{Fase 2: Incorporación valores U resultantes de ensayo experimental a un caso de estudio (simplificación del modelo)}

Si bien es cierto que Tas es un software que permite simular el comportamiento térmico global en edificaciones con un buen nivel de detalles (21) no es específicamente un software de evaluación de puentes térmicos. Por lo cual la manera de analizar estos últimos es a través de la comparación del modelo Tas con presencia de puentes térmicos y posteriormente con la ausencia de éstos. Para llevar a cabo el análisis se deberán ingresar en la opción que define los valores $\mathrm{U}$ de los muros del modelo Tas, los valores del modelo simplificado o valores globales que abarquen el área completa de los muros exteriores del caso de estudio. El valor global será entendido como el valor U ponderado (UP) ya que es la ponderación del\% de muro que abarca el ensayo en cámara térmica (UEC) y el\% de muro restante, cuyo valor U (UM) será calculado de forma manual a partir de la NCh 853.Of91 (17) (Figura 10).

Para calcular el valor U ponderado (UP) se utilizará la fórmula del valor U ponderado incluida en la NCh 853.Of91.

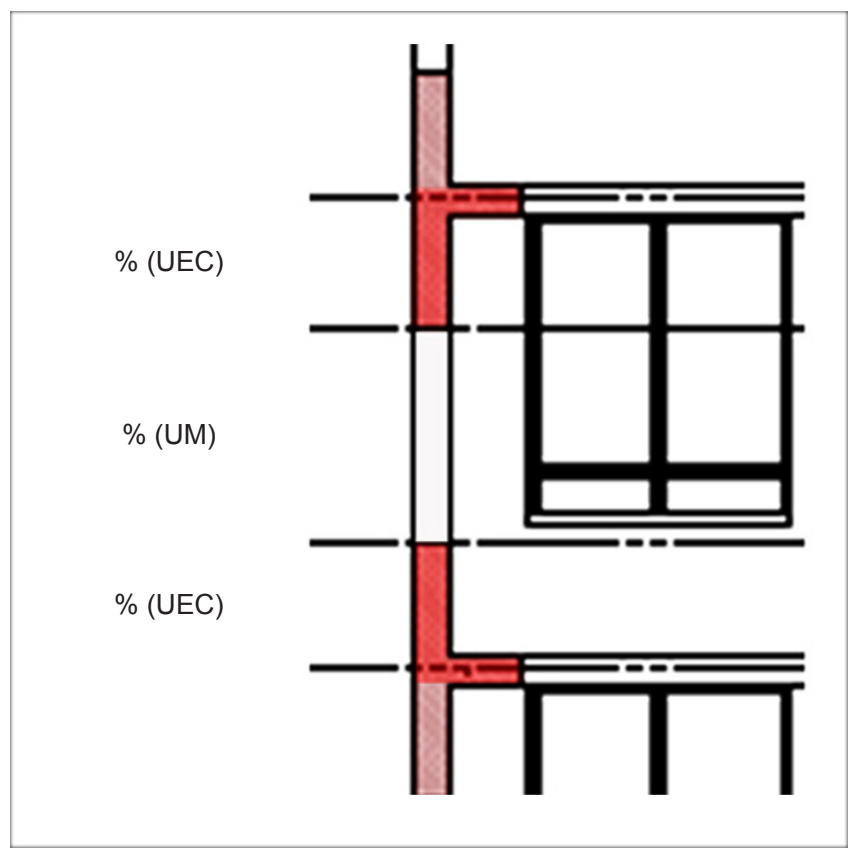

Figura 10. Esquema en corte del área que abarca el valor U resultante de la fase experimental en la cámara térmica (UEC) y el valor U del muro calculado manualmente (UM).
El caso de estudio para evaluar las demandas energéticas es el departamento tipo A-A1 $\left(57,74 \mathrm{~m}^{2}\right)$ ubicado en el tercer piso del bloque A, del condominio Los Encinos en la ciudad de Chillán (Figura 11).

\section{Valores U ponderados (UP).}

Caso 1:

- Valor U ensayo cámara (UEC) $=3,72 \mathrm{~W} / \mathrm{m}^{2} \mathrm{~K}$.

- Valor U muro perimetral (UM) =3,81 W/ $\mathrm{m}^{2} \mathrm{~K}$.

Valor $\mathrm{U}$ ponderado $(\mathrm{UP})=3,75 \mathrm{~W} / \mathrm{m}^{2} \mathrm{~K}$.

Caso 2:

- Valor U ensayo cámara (UEC) =0,86 W/m² K.

- Valor U muro perimetral (UM) = 0,63 W/m² K.

Valor U ponderado (UP) $=0,76 \mathrm{~W} / \mathrm{m}^{2} \mathrm{~K}$.

Caso 3:

- Valor U ensayo cámara (UEC) = 0,90 W/m² K.

- Valor U muro perimetral (UM) $=0,63 \mathrm{~W} / \mathrm{m}^{2} \mathrm{~K}$.

Valor $U$ ponderado $(U P)=0,79 \mathrm{~W} / \mathrm{m}^{2} \mathrm{~K}$.

Caso 4:

- Valor U ensayo cámara (UEC) $=0,69 \mathrm{~W} / \mathrm{m}^{2} \mathrm{~K}$.

- Valor U muro perimetral (UM) =0,63 W/m² $\mathrm{K}$.

Valor U ponderado (UP) $=0,66 \mathrm{~W} / \mathrm{m}^{2} \mathrm{~K}$.

Fase 3: Simulación del caso de estudio en software Tas a partir de los valores $U$ ponderados (UP)

Datos de entrada:

- Programa: Tas V9.2.1.3.

- Recinto de estudio: departamento 301.

- Bloque: A.

- Orientación: nororiente.

- Zonificación: una única zona de estudio correspondiente al departamento 301.

- Rango de temperatura interior: 20-25.

- Infiltraciones de aire: 1 ach las $24 \mathrm{~h}$.

- Aportes internos (I, O, E): 6,7 W/m² las 24 h (valor que comprende aportes por iluminación, ocupación y equipamiento).

- Propiedad de materiales obtenidas de la NCh 853.Of91.

- Condiciones de contorno exterior: base climática horaria. Fuente Meteonorm 6.0 (Figura 12).

Los valores U que se mantendrán fijos para las cuatro simulaciones serán:

- Valor U de ventanas: 5,75 W/m² K.

- Valor U de los muros colindantes con otras unidades: 3,42 $\mathrm{W} / \mathrm{m}^{2} \mathrm{~K}$.

- Valor U tabiques interiores: $0,77 \mathrm{~W} / \mathrm{m}^{2} \mathrm{~K}$.

- Valor U losa de entre piso (flujo vertical ascendente): 3,27 $\mathrm{W} / \mathrm{m}^{2} \mathrm{~K}$; (flujo vertical descendente): $2,24 \mathrm{~W} / \mathrm{m}^{2} \mathrm{~K}$.

\section{RESULTADOS SIMULACIÓN CASO DE ESTUDIO}

Desempeño energético concluido de la demanda arrojada tras la simulación Tas, para el departamento 301, bloque A $\left(57,74 \mathrm{~m}^{2}\right)$, condominio Los Encinos, Chillán. 


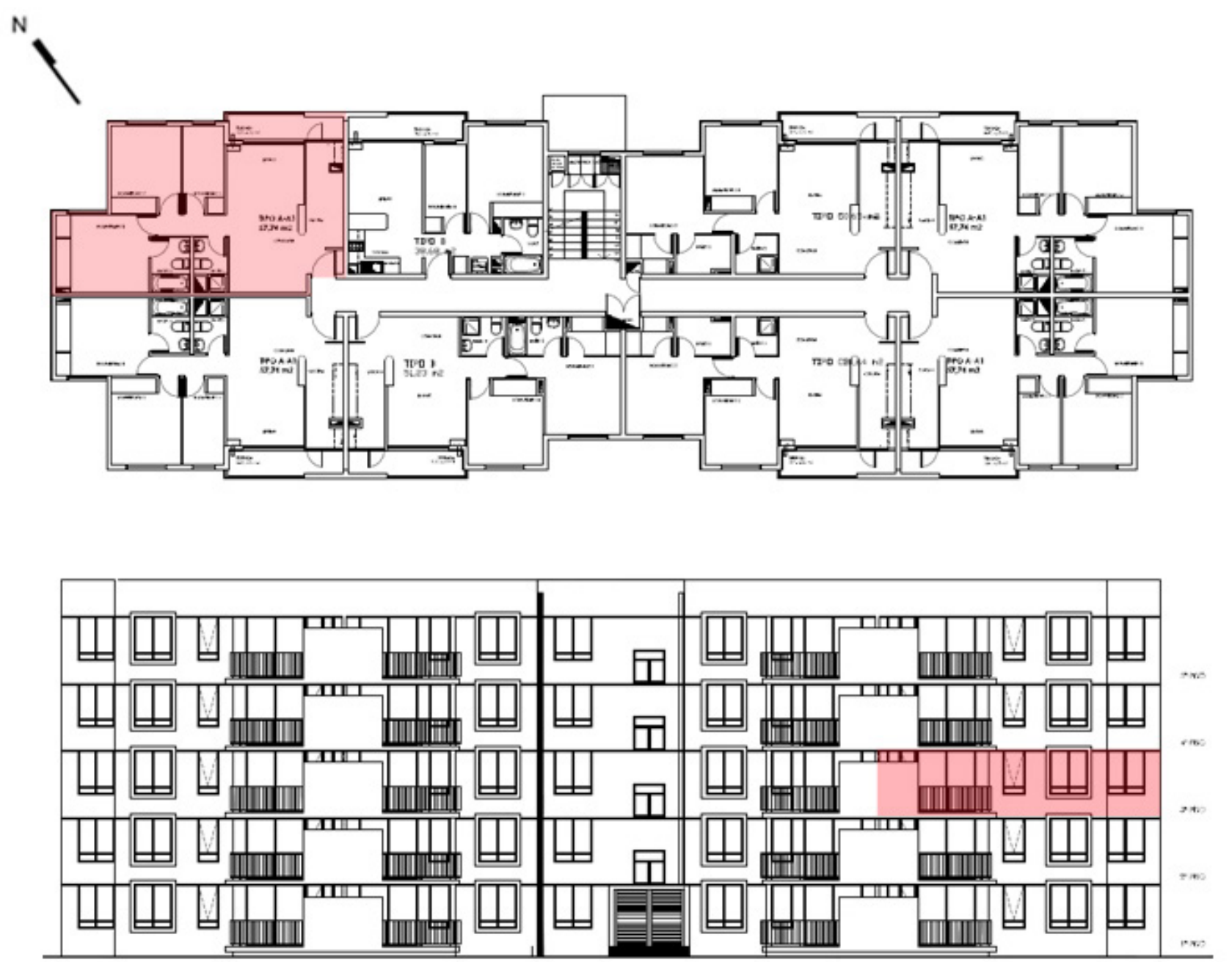

Figura 11. Planta y elevación edificio (caso de estudio).

Caso 1 (sin aislación):

- Demanda anual

- Calefacción: 5911,04 kWh.

- Refrigeración: 182,45 kWh.

- Desempeño energético

- Calefacción: 102,37 kWh/m² año.

- Refrigeración: 3,15 kWh/m² año.

Caso 2 (aislación cara exterior):

- Demanda anual

- Calefacción: 3600,12 kWh.

- Refrigeración: 280,85 kWh.

- Desempeño energético

- Calefacción: 62,35 kWh/m² año.

- Refrigeración: 4,86 kWh/m² año.

Caso 3 (aislación cara interior, presencia de puente térmico):

- Demanda anual

- Calefacción: 3628,34 kWh.

- Refrigeración: 305,52 kWh.

- Desempeño energético

- Calefacción: $62,83 \mathrm{kWh} / \mathrm{m}^{2}$ año.

- Refrigeración: $5.29 \mathrm{kWh} / \mathrm{m}^{2}$ año.
Caso 4 (aislación cara interior, solución puente térmico):

- Demanda anual

- Calefacción: 3527,76 kWh.

- Refrigeración: 316,16 kWh.

- Desempeño energético

- Calefacción: 61,09 kWh $/ \mathrm{m}^{2}$ año.

- Refrigeración: 5,47kWh/m² año.

Conocida la demanda global energética que incluyó la integración de los valores de las singularidades analizadas experimentalmente (resultados de ensayo) y tomando como referencia el caso 2 (aislación por cara exterior del muro) que representa la solución aislada sin presencia de puentes térmicos, se tiene que:

- La demanda anual de calefacción:

Al comparar el caso 2 con el caso 3 (aislación por cara interior, presencia de puente térmico) se tiene que el caso 3 requiere 28,22 kWh extra, sobre la demanda anual de calefacción arrojada por el caso 2, lo que se traduce en que el impacto del puente térmico en las pérdidas de calor es de $0,77 \%$. 


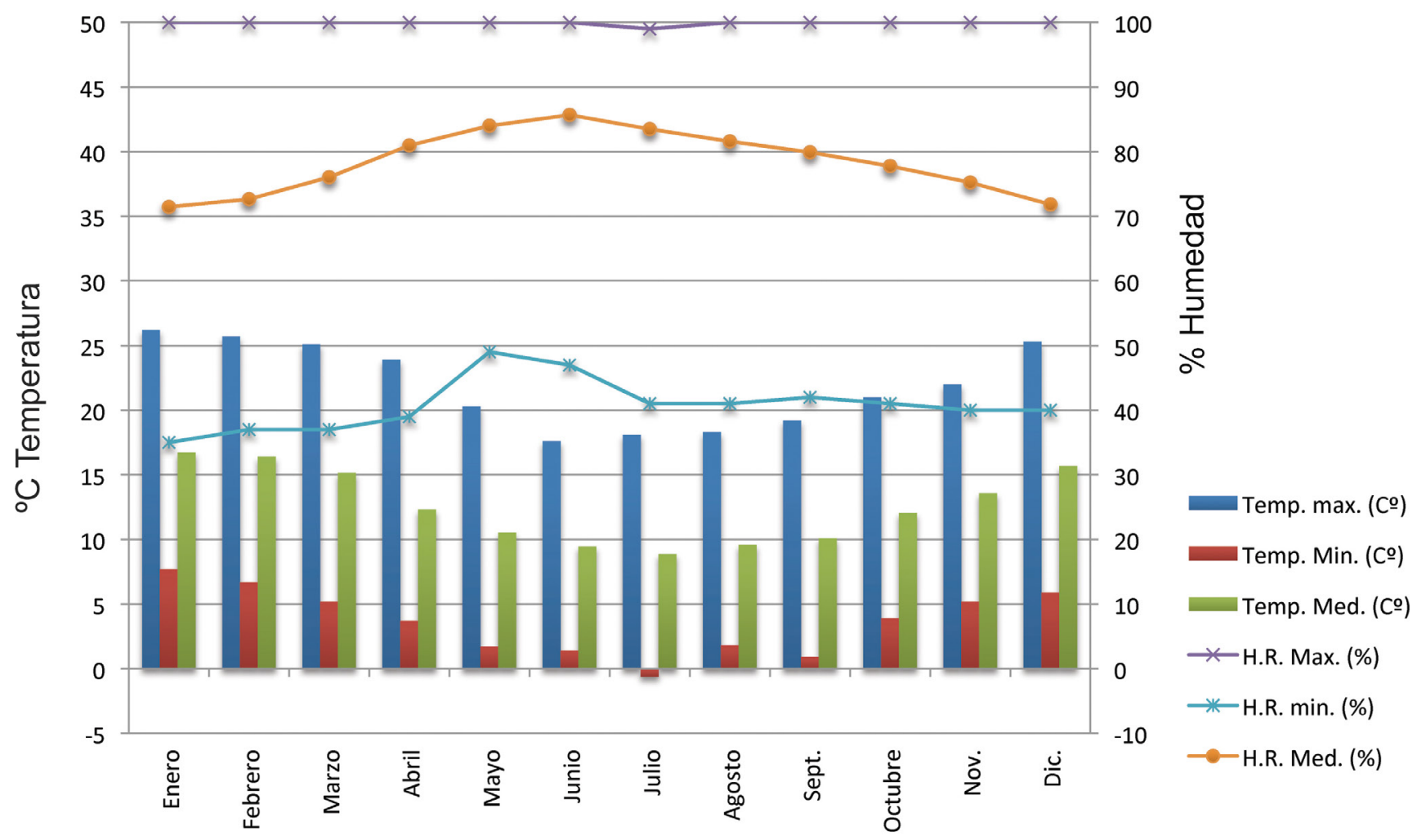

Figura 12. Gráfico de temperaturas del aire y humedad relativa máximas, mínimas y media del ambiente exterior para la ciudad de Chillán. Fuente Meteonorm 6.o.

El caso 4 (aislación por cara interior con solución de puente térmico) tiene un consumo menor en $72,36 \mathrm{kWh}(2 \%)$ comparado con el caso 2.

El caso 1 (solución desprovista de aislación) muestra $2.310,92 \mathrm{kWh}$, igual a un 39,09\% de demanda extra en comparación al caso 2. Diferencia que no proviene de la influencia del puente térmico, sino que se debe principalmente al aporte de la aislación térmica incorporada al caso 2.

- Para efectos de la demanda anual de refrigeración:

Tomando también como referencia el caso 2 se tiene que el caso 3 (aislación por cara interior, con presencia de puente térmico) requiere $24,67 \mathrm{kWh}$ un 8,07\% extra de energía para lograr la temperatura de confort establecida.

El caso 4 (aislación por cara interior con solución de puente térmico) requiere $35,31 \mathrm{kWh}$, un $11,16 \%$, extra sobre la que arrojó el caso 2.

Finalmente para el caso 1 (solución desprovista de aislación), implica 98,4 kWh equivalente a un 35,03\% de energía menos que lo arrojado como demanda por el caso 2.

\section{CONCLUSIONES}

En relación al nudo en análisis «frente de forjado», tras la comparación de las demandas anuales de energía en calefacción, entre la solución con aislación por cara exterior del muro y la solución por la cara interior (presencia de puente térmico) podemos concluir la baja incidencia de dicho puente, representado por una diferencia de $0,77 \%$ (Figura 13).

Otro punto destacable en esta investigación vinculada a la baja incidencia del puente térmico es la diferencia que presenta con la mayoría de los resultados obtenidos me- diante análisis teóricos realizados tanto con herramientas de simulación (22) como cálculos llevados en base a valores tabulados (13), destacando la mayor diferencia en el valor entregado mediante ensayo experimental para el caso 2 (aislación por cara exterior). Resultados que abren el debate entre lo que arrojan análisis teóricos y ensayos experimentales, ambas metodologías supuestamente comparables.

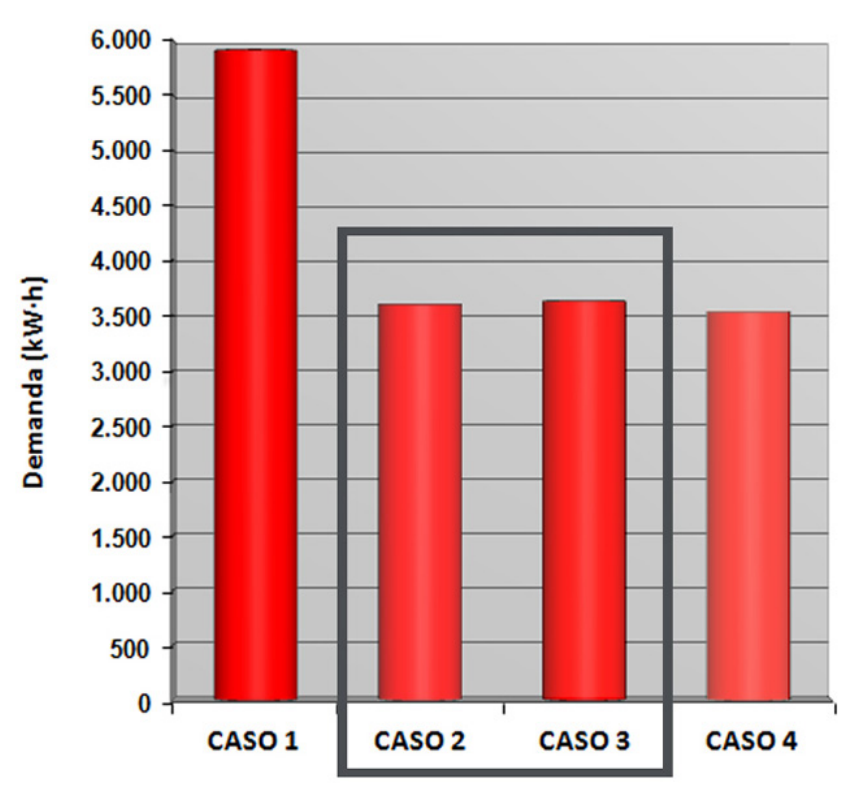

Figura 13. Gráfico de la demanda energética anual de calefacción donde se compara la diferencia entre el caso 2 (aislación por cara exterior del muro) y el caso 3 (aislación por cara interior del muro, con presencia de puente térmico). 
Referente a las demandas de refrigeración éstas si evidencian un impacto de mayor relevancia. Ya que en relación al caso 2 el caso 3 presenta un 8,07\% de consumo extra, mientras que el caso 4 aumenta en un 11,16\%. Esto responde en gran parte a que al tener la capa de aislación térmica por la cara interna del recinto habitable, las fuentes de calor interior encuentran en dicha aislación una barrera, conservando el calor y en consecuencia aumentando la demanda de refrigeración, a diferencia del caso 2 donde la masa del muro absorberá parte del calor generado. Para el caso 1 la ausencia de aislación permitirá que el calor interior no encuentre barreras en su flujo, trayendo como efecto la disminución en las demandas de enfriamiento (Figura 14). Las demandas de refrigeración son sensibles a estas configuraciones, ya que actúan en un rango de tiempo acotado, que son las horas al día en que se requiere enfriar el ambiente interior.

El punto de mayor relevancia en este estudio es el comportamiento de las temperaturas superficiales, ya que éstas presentaron diferencias significativas para el caso 3 (presencia de puente térmico) donde se generó una diferencia de $4,99^{\circ} \mathrm{C}$ entre el punto de la losa más próximo al muro y el punto más lejano de medición (Figura 15).

Cabe destacar que debido a las diferencias de temperaturas interior-exterior presentadas entre los casos de estudio se aplicó, como apoyo al análisis, el factor de temperatura de la superficie interior $f_{\mathrm{Rsi}}$ (23) como factor comparativo entre casos (Figura 15), ya que éste está dado por el cociente entre la diferencia de temperatura superficial interior y la del ambiente exterior y la diferencia de temperaturas del ambiente interior y exterior.

Las diferencias de temperaturas en las superficies antes mencionadas cobran valor ante un posible descenso de la temperatura del aire del recinto o el aumento de la humedad interior, trayendo consigo el riesgo de condensación para la superficie más fría.

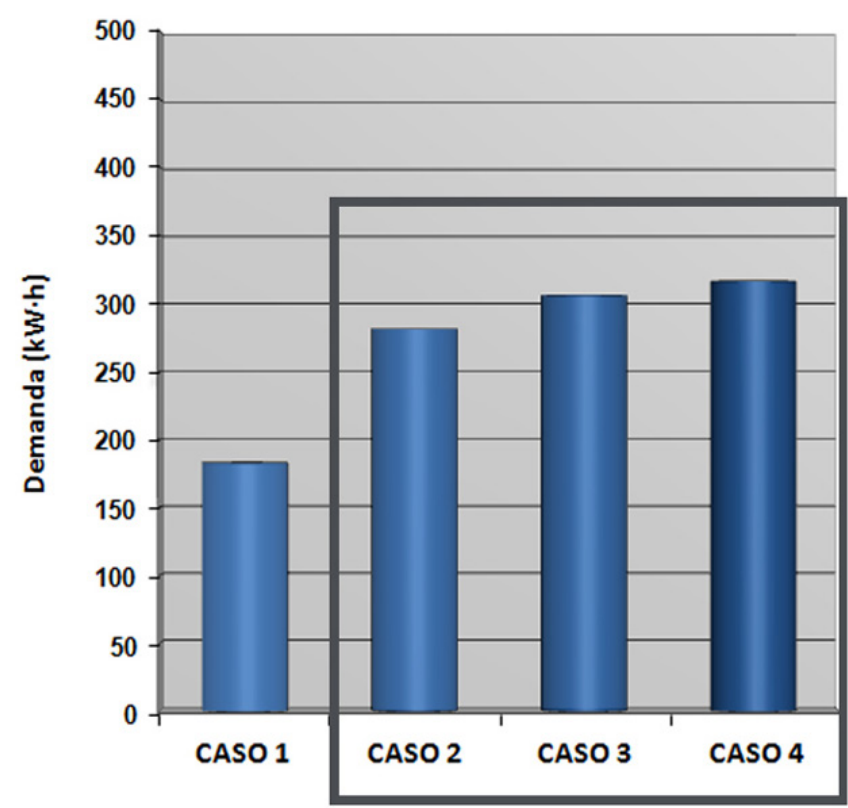

Figura 14. Gráfico de la demanda energética anual de refrigeración donde se visualiza el incremento de energía al incorporar aislación por la cara interior tanto del muro (caso 3) como del muro y la losa (caso 4), en comparación con la solución de aislación por la cara exterior del muro (caso 2).
Además hay que considerar el factor geométrico propio de la zona afectada por el puente (ángulo recto en encuentro muro-losa) que implica dificultad para la circulación de aire y con ello el deficiente secado de condensaciones superficiales. Dicho factor formal no sólo expone la mencionada zona a la formación de mohos sino también al riesgo de saturación de humedad intersticial en el material aislante, bajando su resistencia térmica y con ello potenciales pérdidas de calor (5) (22).

Por lo tanto, después de evaluar el comportamiento de las temperaturas superficiales en un puente térmico lineal y en consideración de la dificultad de ventilación con la que cuentan, producto de su geometría, se reafirman la necesidad de tratar los puentes térmicos puntuales (rincones) con mayor
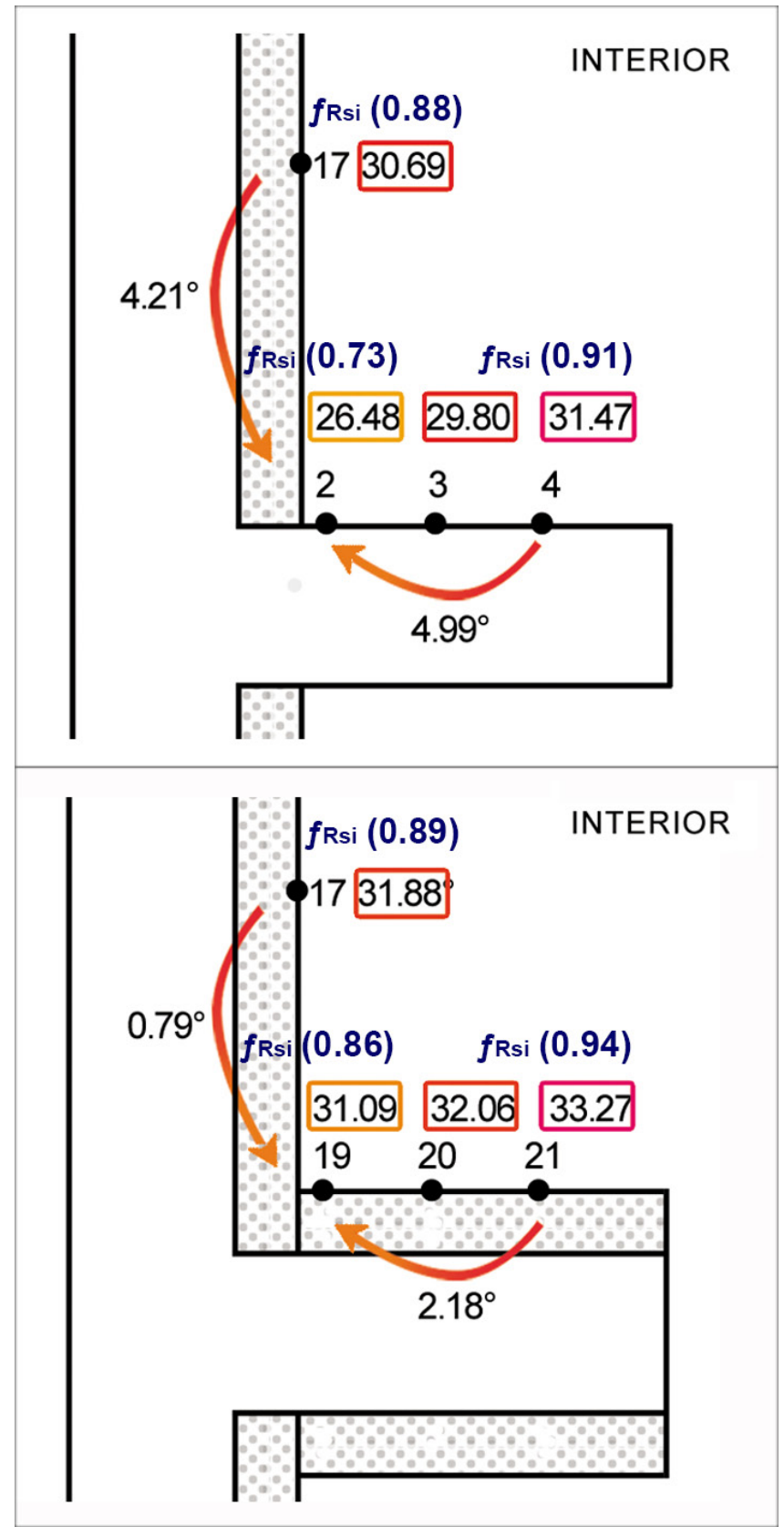

Figura 15. Levantamiento de las temperaturas superficiales y factores de temperatura de la superficie interior aplicado, para el caso 3, aislación por la cara interior del muro con presencia de puente térmico (arriba), y el caso 4, aislación por la cara interior del muro, con solución de puente térmico (abajo). 


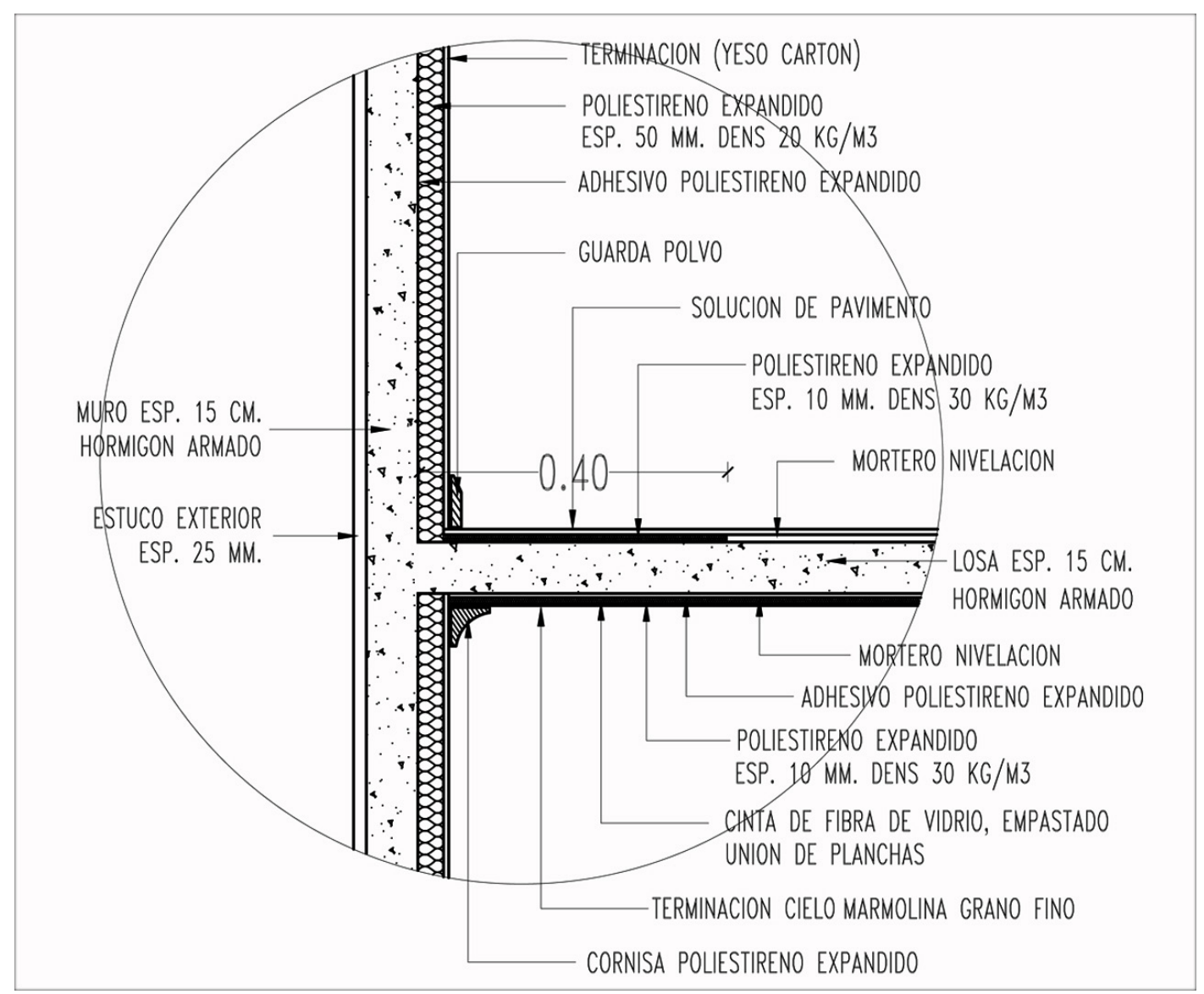

Figura 16. Detalle constructivo que representa solución para disipación de puente térmico.

atención respecto del riesgo de condensación. Más aún teniendo en cuenta que en el cálculo de pérdida de calor muchas veces se desprecian por tratarse de la intersección de puentes térmicos lineales, no siendo evaluados como singularidad.

Respecto de la solución propuesta para disipar el puente térmico, el caso 4 (capa de aislación sobre la losa) no sólo logra subir las temperaturas superficiales sino que disminuye considerablemente la diferencia entre ellas, evitando un punto particularmente frío en la zona de baja ventilación (rincón) (Figura 15).

Además en relación a este ítem, las pruebas demostraron que con $40 \mathrm{~cm}$ de longitud que abarque dicha capa de aislación sobre y bajo la losa es suficiente para lograr los efectos recién descritos sobre la zona de puente. Por un tema constructivo se deja la posibilidad que la plancha de poliestireno correspondiente al cielo cubra toda la superficie del recinto, con el fin de que no acuse el cambio de material (Figura 16).

Finalmente podemos agregar que el impacto derivado del puente térmico analizado cobra relevancia en edificaciones cuyos muros incorporan aislamiento térmico, a diferencia de una edificación sin protección térmica en muros, como es el caso 1 de este análisis, donde las zonas críticas definidas por los puentes térmicos se tornan poco significativas.

\section{FUTURAS LÍNEAS DE INVESTIGACIÓN}

Según los resultados de los valores U entregados por los ensayos experimentales, se genera una diferencia entre el caso 2 (aislación por el exterior del muro) y el caso 4 (aislación por el interior de muro, como también sobre y bajo de la losa), arrojando este último caso un valor U inferior que el caso 2 que representa la ausencia de puente térmico. Profundizar en los parámetros que determinan dicha diferencia se plantea como una variable interesante de investigación futura.

Por otro lado sería de gran valor incorporar al análisis el aporte de la masa térmica (inercia) para el caso de la aislación por cara exterior del muro en comparación a la solución por interior (comportamiento en el tiempo tras períodos sin aportes de calefacción) con el fin de poder contrastar con mayores antecedentes dichas soluciones de mejoramiento térmico para muros.

Respecto al comportamiento de las temperaturas superficiales registradas en este trabajo, se visualiza el aporte de poder profundizar en el riesgo de condensación asociado a la relación que se establece entre las condiciones técnicas de la solución constructiva para el puente térmico analizado y las condiciones ambientales del caso de estudio (particularmente en las condiciones de borde interno). Esto permitiría poder proyectar el comportamiento de dicho puente a otras localidades conforme cambien las condiciones climáticas.

\section{AGRADECIMIENTOS}

Los autores agradecen al Magíster en Hábitat Sustentable y Eficiencia Energética y al CITEC UBB por su apoyo técnico en el desarrollo de esta investigación y al Ingeniero en Construcción Rodrigo Figueroa por su asesoría y colaboración en las simulaciones energéticas. 


\section{REFERENCIAS}

(1) Agencia Chilena de Eficiencia Energética (AChEE) (2013). Reporte 2013 AChEE. Santiago de Chile. Disponible en https://issuu.com/guias-agencia-ee/docs/reporte_2013.

(2) Corporación de Desarrollo Tecnológico de la Cámara Chilena de la Construcción (2010). Reacondicionamiento térmico de viviendas en uso, Santiago de Chile.

(3) Instituto Nacional de Estadísticas (INE) (2012). Informe anual de edificación 2011, Santiago de Chile.

(4) Theodosiou, T. G., Papadopoulos, A. M. (2008). The impact of thermal bridges on the energy demand of buildings with double brick wall constructions. Energy and Buildings, 40: 2083-2089. doi: http://dx.doi.org/10.1016/j. enbuild.2008.06.006.

(5) Regodón, M. I., Tenorio Ríos, J. A. (2005). Pérdidas de calor y formación de condensaciones en los puentes térmicos de los edificios. En Primeras Jornadas de Investigación en Construcción. España: Instituto de Ciencias de la Construcción Eduardo Torroja.

(6) Ministerio de Vivienda y Urbanismo (MINVU) Chile (2013). D.S. No 47 DE 1992, Ordenanza General de Urbanismo y Construcción (OGUC), de las condiciones de habitabilidad art. 4.1.1. Santiago de Chile.

(7) Escorcia, O., et al. (2012). Mejoramientos de envolvente para la eficiencia energética de viviendas en el centro-sur de Chile. Informes de la Construcción, 64(528): 563-574, doi: http://dx.doi.org/10.3989/ic.11.143.

(8) Alías, H. M., Jacobo, G. J. (2007). Reducción del consumo energético de edificios en torre mediante atenuaciones de puentes térmicos en su envolvente, simulaciones con QUICK II". Avances en Energías Renovables y Medio Ambiente, 11: 27-32.

(9) Instituto Nacional de Normalización, INN-Chile (2008). Aislación térmica - Determinación de propiedades de transmisión térmica en estado estacionario y propiedades relacionadas - Cámara térmica calibrada y de guarda. NCh 851 Of20o8. Santiago de Chile.

(10) Zalewski, L., Lassue, S., Rousse, D., Boukhalfa, K. (2010). Experimental and numerical characterization of thermal bridges in prefabricated building walls. Energy Conversion and Management, 51(12): 2869-2877, doi: http://dx.doi. org/10.1016/j.enconman.2010.06.026.

(11) Asdrubali, F., Baldinelli, G., Bianchi, F. (2012). A quantitative methodology to evaluate thermal bridges in buildings. Applied Energy, 97: 365-373, doi: http://dx.doi.org/10.1016/j.apenergy.2011.12.054.

(12) Instituto Nacional de Normalización, INN-Chile (2008). Puentes térmicos en construcción de edificios - Flujos de calor y temperaturas de superficie - parte 1: Métodos generales de cálculo. NCh 3136/1 Of20o8. Santiago de Chile.

(13) Asociación Española de Normalización y Certificación, AENOR (2011). Puentes térmicos en la edificación. Transmitancia térmica lineal. Métodos simplificados y valores por defecto. UNE-EN ISO 14683:2007. Madrid, España.

(14) Tilmans, A., Van Orshoven (2010). Software and Atlases for evaluating thermal bridges. Disponible en http://www. buildup.eu/sites/default/files/content/P198_Software_and_atlases_for_evaluating_thermal_bridges_o.pdf.

(15) Muñoz, C., Bobadilla A. (2012). Simulación y evaluación de puentes térmicos. Soluciones constructivas típicas aprobadas por la Norma Térmica para elementos verticales en estructura de madera y metálicos en la Zona 4. Simulaciones con Therm y Usai y evaluación con Método de Cámara Térmica. Revista de la Construcción, 12(22): 92-111.

(16) Ministerio de Vivienda y Urbanismo (MINVU) (2012). Listado Oficial de Soluciones Constructivas para Acondicionamiento Térmico. Disponible en http://www.minvu.cl/opensite_20070611111640.aspx

(17) Instituto Nacional de Normalización, INN-Chile (1991). Acondicionamiento térmico - Envolvente térmica de edificios - Calculo de resistencias y transmitancias térmicas. NCh 853.Of91. Santiago de Chile.

(18) Environmental Design Solutions Limited (2015). Tas Software. Recuperado el 7 de septiembre de 2015, http://www. edsl.net/main/Software.aspx

(19) Asociación Española de Normalización y Certificación, AENOR (1997). Determinación de las propiedades de transmisión térmica en régimen estacionario. Métodos de la caja caliente guardada y calibrada (ISO 8990: 1994). Madrid, España.

(20) Ministerio de Fomento (2014). Documento de Apoyo al Documento Básico, Ahorro de Energía, DA DB-HE / 3 Puentes térmicos.

(21) García-Alvarado, R., González, A., Bustamante, W., Bobadilla, A., Muñoz, C. (2014). Características relevantes de la simulación energética de viviendas unifamiliares. Informes de la Construcción, 66(533), doi: http://dx.doi.org/10.3989/ ic.12.108.

(22) Ben Larbi, A. (2005). Statistical modelling of heat transfer for thermal bridges of buildings. Energy and Buildings, 37: 945-951, doi: http://dx.doi.org/10.1016/j.enbuild.2004.12.013.

(23) Instituto Nacional de Normalización, INN-Chile (2008). Características higrotérmicas de los elementos y componentes de edificación - Temperatura superficial interior para evitar la humedad superficial crítica y la condensación intersticial - Métodos de cálculo. NCh 1973 Of20o8. Santiago de Chile. 